\title{
Determination of fatty acid content in sheep milk by means of near infrared spectroscopy
}

\author{
Táňa Lužová1, Květoslava Šustová ${ }^{1}$, Jan Kuchtík², Jiří Mlček ${ }^{3}$, Lenka Vorlová4, \\ Daniela Sumczynski ${ }^{3}$
}

\begin{abstract}
${ }^{1}$ Mendel University in Brno, Faculty of Agronomy, Department of Food Technology, ${ }^{2}$ Department of Animal Breeding, Brno, Czech Republic

${ }^{3}$ Tomas Bata University in Zlin, Faculty of Technology, Department of Food Analysis and Chemistry, Zlín, Czech Republic

${ }^{4}$ University of Veterinary and Pharmaceutical Science Brno, Faculty of Veterinary Hygiene and Ecology, Department of Milk Hygiene and Technology, Brno, Czech Republic
\end{abstract}

Received October 17, 2014

Accepted February 25, 2015

\begin{abstract}
The study focused on the use of the Fourier transform near infrared spectroscopy in determining the content of selected fatty acids in raw non-homogenized sheep milk. The raw sheep milk sample spectra were scanned in reflectance mode using the FT NIR Antaris spectrophotometer. The reliable functional calibration models were created for estimation of the contents of myristic, oleic, lauric, palmitic, and stearic acids (with calibration correlation coefficients of $\mathrm{R}=0.999$; $0.999 ; 0.993 ; 0.992 ; 0.858)$ and with standard errors $\mathrm{SEC}=0.056 ; 0.152 ; 0.066 ; 0.367 ; 1.36 \%$.
\end{abstract}

\section{Caprinic acid, lauric acid, myristic acid, palmitic acid, stearic acid, oleic acid}

Compared to cow milk, sheep milk contains more fat, more proteins and the dry matter content increases naturally with these values. It has been determined that the main triglycerides in the sheep milk fat consisted predominantly of three fatty acids (FA) $\left(\mathrm{C}_{14}\right.$, $\mathrm{C}_{16}$ a $\mathrm{C}_{18: 1}$ ) in combination with $\mathrm{C}_{4}$ and $\mathrm{C}_{6}$ short chain fatty acids (De la Fuente et al. 2013).

To determine the composition and quality of milk, Fourier transform near-infrared (FT NIR) spectrometry has been used in recent years. Most studies deal predominantly with determination of the component parts of cow milk. The analysis of sheep milk, especially comparison of determination accuracy of fresh sheep milk composition in the transmittance mode as well as dry sheep milk in the reflectance mode using FT NIR spectrometry was researched by Nunez-Sanchez et al. (2002). Both methods obtained high calibration coefficients (higher than 0.9) for all the determined components (total protein, casein, fat, total solids). Sustová et al. (2006) designed a method measuring sheep milk samples using a speculum in the integrating sphere. Using the partial least square (PLS) method, the following calibration results was achieved: R: 0.983 (dry matter); 0.989 (fat); 0.997 (proteins); 0.997 (casein); 0.980 (lactose), and 0.973 (urea).

Mouazen et al. (2009) used the FT NIR spectrophotometer to determine fat, proteins, lactose, fat-free dry matter, and ash content as well as density, freezing point and $\mathrm{pH}$ of sheep milk. Samples from 50 sheep bred in various feeding systems and of varying genotypes were obtained. They were measured in the spectrum of wavelengths starting from 350-2,500 nm. A model was developed using partial least squares regression (PLSR), characterized by a good predictive ability for determination of almost all indicators $\left(\mathrm{R}^{2}: 0.84-0.90\right.$ and $\mathrm{RPD}$ (residual prediction deviation): 2.34-3.34). But the calibration model for fat and $\mathrm{pH}$ had very low values of $\mathrm{R}^{2}$ : $0.14-0.73$ and RPD: $1.11-1.64)$.

Address for correspondence:

Ing. Jiří Mlček, Ph.D.

Department of Food Analysis and Chemistry

Faculty of Technology, Tomas Bata University in Zlin

nám. T.G. Masaryka 275, 76272 Zlín, Czech Republic
Phone: +420 576033030

Fax: +420576031 111

E-mail: mlcek@ft.utb.cz

http://www.vfu.cz/acta-vet/actavet.htm 
Determination of basic components of sheep milk is also discussed in the study by Procházková et al. (2010) who examined 33 samples of sheep milk from a sheep farm in the Northern Moravia Region of the Czech Republic. The following indicators were determined in the samples: protein content, lactose content, total content of dry matter, content of fat-free dry matter, and titratable acidity. All stated indicators were determined by standard methods as well as by FT NIR spectrometry. Calibration models of high reliability were obtained for all indicators under investigation $\left(\mathrm{R}^{2}\right.$ was close to 1$)$. It results from this paper that the FT NIR spectrometry method is a highly reliable and appropriate method to determine the basic indicators of sheep milk.

Aulrich and Molketin (2009) studied the influence of conventional and organic agriculture upon structure of fatty acids in cow milk, using FT NIR spectrometry. They focused on determining fatty acids that were influenced most by season and by different feeding rations. The results of their work point at the possibility of determining especially $\omega-3$ FA (with C18:3 and C20:5) using NIR spectroscopy.

Our study focused on verification of the possibility of determining the content of selected fatty acids (C10:0 - caprinic acid, C12:0 - lauric acid, C14:0 - myristic acid, C16:0 palmitic acid, C18:0 - stearic acid, and C18:1n9c - oleic acid) in raw non-homogenized sheep milk using FT NIR spectrometry.

\section{Materials and Methods}

Raw non-homogenized sheep milk was obtained on the Ondruch sheep farm in Valašská Bystřice. Over the whole lactation period, five collections of 19 individual samples of sheep milk were taken. After collection, milk was cooled down to the temperature of 4 to $6^{\circ} \mathrm{C}$, preserved using an antimicrobial tablet Broad Spectrum Microtabs II, stored in cooling containers, and transferred to the Department of Food Technology, Mendel University in Brno, where the samples were meted on a FT NIR spectrometer. Referential analyses to determine fatty acids (FA) C10:0 - caprinic, C12:0 - lauric, C14:0 - myristic, C16:0 - palmitic, C18:0 - stearic, and C18:1n9c - oleic were performed at the Department of Chemistry and Biochemistry, Mendel University in Brno. Referential values for spectrophotometer calibration to determine fatty acids are shown in Table 1. Additional fatty acids were determined in samples in the laboratory, including e.g., C4:0, C6:0, C8:0, etc., but their concentrations were very low. The method of FT NIR spectroscopy is not suitable for determination of minor components in a sample. The spectral signal of the component (FA) to be determined is very weak and could disappear e.g. in spectral noise, therefore it is not possible in this case to create calibration models for their determination.

\section{Referential analytic methods}

The analyses of fatty acids in sheep milk were performed on gas chromatography (HP4890) with DB-23 capillary column $(60 \mathrm{~m} \times 0.25 \mathrm{~mm} \times 0.25 \mu \mathrm{m})$. For the measurement, a temperature program of $100{ }^{\circ} \mathrm{C} *$ $3 \mathrm{~min} * 10^{\circ} \mathrm{C} / \mathrm{min} * 170{ }^{\circ} \mathrm{C} * 0 \mathrm{~min} * 4^{\circ} \mathrm{C} / \mathrm{min} * 230{ }^{\circ} \mathrm{C} * 8 \mathrm{~min} * 5{ }^{\circ} \mathrm{C} / \mathrm{min} * 250{ }^{\circ} \mathrm{C} * 15 \mathrm{~min}$ was selected, with injector temperature of $270{ }^{\circ} \mathrm{C}$, detector temperature of $280{ }^{\circ} \mathrm{C}$, and application of $2 \mu$. The carrier gas was nitrogen. A flame ionization detector was attached to the column output. Final chromatograms

Table 1. Reference values for calibration of fatty acids (FA) in sheep milk (\%)

\begin{tabular}{llrrrr}
\hline Indicator & $\mathrm{n}$ & Min & Max & $\mathrm{x}_{\mathrm{p}}$ & $\mathrm{S}_{\mathrm{x}}$ \\
\hline $\mathrm{C} 10: 0$ & 95 & 1.34 & 6.68 & 3.70 & 1.23 \\
$\mathrm{C} 12: 0$ & 95 & 1.21 & 3.68 & 2.35 & 0.57 \\
$\mathrm{C} 14: 0$ & 95 & 6.57 & 13.11 & 9.37 & 1.47 \\
$\mathrm{C} 16: 0$ & 95 & 25.04 & 37.31 & 29.43 & 2.93 \\
$\mathrm{C} 18: 0$ & 95 & 8.55 & 20.36 & 14.95 & 2.66 \\
C18:1n9c & 95 & 18.56 & 32.72 & 25.27 & 3.36 \\
\hline
\end{tabular}

$\mathrm{n}$ - number of samples, Min a Max - minimal and maximum values, $\mathrm{x}_{\mathrm{p}}-$ mean values, $\mathrm{S}_{\mathrm{x}}-$ standard deviation, C10:0 - caprinic acid, C12:0 - lauric acid, C14:0 - myristic acid, C16:0 - palmitic acid, C18:0 - stearic acid and C18: $\ln 9 \mathrm{c}-$ oleic acid 
were processed with CSWstation (version 1.7, Data Apex). Standard of fatty acid mixture SUPELCO 37 component FAME mix, cat. number 47885-U + linoleic acid conjugated methyl ester, cat. number O5632 was used.

\section{NIR spectra measurement}

Spectroscopic analyses were performed on FT NIR Antaris spectrophotometer (ThermoNicolet, USA). Although sheep milk samples were conserved using Broad Spectrum Microtabs II, according to Šustová et al. (2007) that had no influence upon spectral information of the analyzed sample. Before the spectroscopy analysis, sheep milk was tempered at $40{ }^{\circ} \mathrm{C}$, stirred around, and subsequently cooled down to $20^{\circ} \mathrm{C}$. This procedure was selected according to recommendations given by Chen et al. (1999), as it is necessary to convert the fat into its liquid form and disperse it evenly in the whole sample volume. The analyzed samples were scanned in the spectral range of $12,500-4,000 \cdot \mathrm{cm}^{-1}$ wave numbers, corresponding to $1,000-2,500$ wavelengths, with a scanning time of one spectrum $\sim 1.5 \mathrm{~min}$. The samples were measured in a Petri dish with a diameter of $6 \mathrm{~cm}$ in reflectance mode on the integrating sphere of the device. Ray reflection was ensured by metal mirror with a reflective area of 0.3 $\mathrm{mm}$. The number of one spectrum scans was 100 with a spectral resolution of $8 \cdot \mathrm{cm}^{-1}$ according to Procházková et al. (2010) and Mlček et al. (2013). To create calibration models for quantitative and qualitative analyses, the TQ Analyst software was used. The subsequent calibrations were validated using cross validation so that we could determine the accurate prediction ability of the created model in the indicator to be determined (Mlček et al. 2006).

\section{Results}

A total of 95 sheep milk samples were analyzed, where the content of selected fatty acids was determined. To determine the fatty acid content in sheep milk, some spectra were subjected to first or second derivation and such a region range was selected to obtain the best possible calibration and validation results. Table 2 shows used spectra adjustments and region ranges for individual fatty acids. Using Spectrum Outlier, PC Scores and Leverage diagnostic (Šustová et al. 2007) tools, the remote standards were identified which - based on spectral or concentration differences - did not fit into calibration data file and so they were removed. These standards did not contain key data for the creation of calibration models. The calibrations were created using the PLS method (Mlček et al. 2011).

Table 2. Editing spectra and regions selected areas of wave numbers for the calibration of fatty acids in sheep milk.

\begin{tabular}{llllc}
\hline \multirow{2}{*}{ Indicator } & $\mathrm{n}$ & Editing spectra & \multicolumn{2}{c}{ Selected region for calibration } \\
\cline { 4 - 5 } & & & \multicolumn{1}{c}{ Editing } & Wavenumber $\left(\cdot \mathrm{cm}^{-1}\right)$ \\
\hline $\mathrm{C} 10: 0$ & 87 & First derivation & $1^{\text {st }}$ Derivative in range & $10.001-4.005$ \\
$\mathrm{C} 12: 0$ & 87 & First derivation & $1^{\text {st }}$ Derivative in range & $10.001-4.005$ \\
$\mathrm{C} 14: 0$ & 87 & First derivation & $1^{\text {st }}$ Derivative in range & $10.001-4.005$ \\
$\mathrm{C} 16: 0$ & 88 & - & $1^{\text {st }}$ Derivative in range & $10.001-4.170$ \\
$\mathrm{C} 18: 0$ & 86 & - & Spectrum range & $8.947-4.005$ \\
$\mathrm{C} 18: 1 \mathrm{n} 9 \mathrm{c}$ & 89 & Second derivation & Spectrum range & $10.001-4.005$ \\
\hline
\end{tabular}

$\mathrm{n}$ - number of samples, C10:0 - caprinic acid, C12:0 - lauric acid, C14:0 - myristic acid, C16:0 - palmitic acid, C18:0 - stearic acid, C18: $\ln 9 \mathrm{c}-$ oleic acid

Calibration results of fatty acids and PLS factor values are shown in Table 3 . The lowest number of PLS factors of 5 was found for caprinic acid; by contrast, the highest number of PLS 10 was found for myristic, palmitic, and stearic acids. The higher number of PLS was probably connected to a narrower concentration range of given values and a greater standard error of values. In all models the PRESS function had a declining trend, testifying of the robustness of calculation models. As an example, the PRESS function course with a declining trend is shown in Fig. 1. Correlation coefficient of calibrations (R) ranged 
Table 3. Calibration results of fatty acids (FA) of sheep milk.

\begin{tabular}{lcccccc}
\hline Indicator & $\mathrm{n}$ & $\mathrm{R}$ & $\mathrm{SEC}(\%)$ & $\mathrm{CCV}(\%)$ & $\mathrm{y}=\mathrm{bx} \pm \mathrm{a}$ & PLS \\
\hline $\mathrm{C} 10: 0$ & 87 & 0.911 & 0.505 & 13.65 & $\mathrm{y}=0.8308 \mathrm{x}+0.626$ & 5 \\
$\mathrm{C} 12: 0$ & 87 & 0.993 & 0.066 & 2.81 & $\mathrm{y}=0.9869 \mathrm{x}+0.0307$ & 8 \\
$\mathrm{C} 14: 0$ & 87 & 0.999 & 0.056 & 0.60 & $\mathrm{y}=0.9986 \mathrm{x}+0.0131$ & 10 \\
$\mathrm{C} 16: 0$ & 88 & 0.992 & 0.367 & 1.25 & $\mathrm{y}=0.9842 \mathrm{x}+0.4637$ & 10 \\
$\mathrm{C} 18: 0$ & 86 & 0.858 & 1.360 & 9.10 & $\mathrm{y}=0.7362 \mathrm{x}+3.9437$ & 10 \\
$\mathrm{C} 18: \ln 9 \mathrm{c}$ & 89 & 0.999 & 0.152 & 0.60 & $\mathrm{y}=0.998 \mathrm{x}+0.0517$ & 9 \\
\hline
\end{tabular}

$\mathrm{n}-$ number of samples, $\mathrm{y}=\mathrm{bx}+\mathrm{a}=$ regression line, SEC - standard error of calibration, CCV - calibration coefficient of variation, $\mathrm{R}$ - correlation coefficient, PLS - number of partial least square factors, C10:0 - caprinic acid, C12:0 - lauric acid, C14:0 - myristic acid, C16:0 - palmitic acid, C18:0 - stearic acid, C18:1n9c - oleic acid

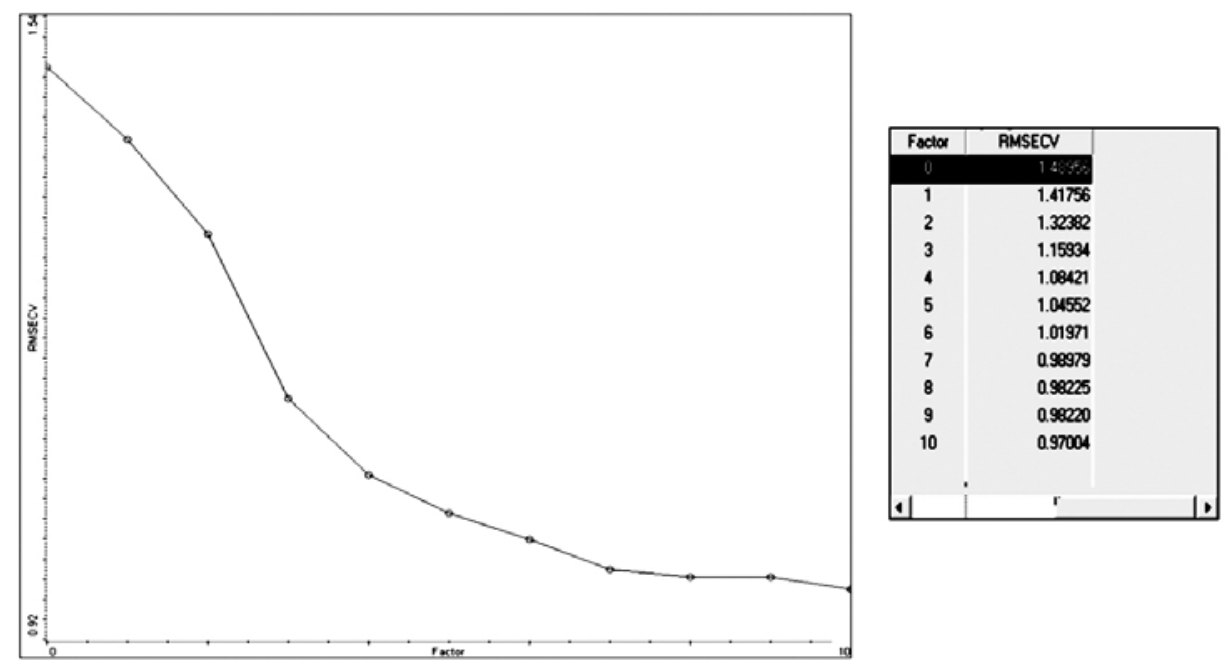

Fig. 1. PRESS function to determine the myristic acid in sheep milk with 10 PLS factors

between 0.999 for myristic and oleic acids and 0.858 for stearic acid with standard errors of calibrations (SEC) starting from $0.056 \%$ and $0.152 \%$ up to $1.360 \%$ as shown in Table 3 . For reliability verification of created calibration models, cross validation with the same sample set was used, which was characterized by correlation coefficient of validation (R) and its standard error of prediction (SEP) (Table 4). The best validation results were achieved in determination of stearic acid where $\mathrm{R}=0.778$ and $\mathrm{SEP}=1.680 \%$. In contrast, the lowest $\mathrm{R}$ values were recorded in the model for determination of caprinic acid $\mathrm{R}=0.618 \pm 0.974 \%$. Standard errors of validation ranged between 0.443 to $1.970 \%$.

Figure 2 (Plate I) represents a graphic expression of calibration and validation correlation coefficient dependencies for stearic acid where the largest overlap of calibration and validation regression lines occurred. Reliabilities of calibrations were further reviewed using the so called calibration coefficient of variation and calibration coefficient of prediction (CCV and PCV) (Tables 3 and 4). 
Table 4. Validation results of fatty acids (FA) of sheep milk.

\begin{tabular}{lccccc}
\hline Indicator & $\mathrm{n}$ & $\mathrm{R}$ & $\mathrm{SEP}(\%)$ & $\mathrm{PCV}(\%)$ & $\mathrm{y}=\mathrm{bx} \pm \mathrm{a}$ \\
\hline $\mathrm{C} 10: 0$ & 87 & 0.618 & 0.974 & 26.41 & $\mathrm{y}=0.4498 \mathrm{x}+2.0232$ \\
$\mathrm{C} 12: 0$ & 87 & 0.647 & 0.443 & 18.88 & $\mathrm{y}=0.4981 \mathrm{x}+1.1752$ \\
$\mathrm{C} 14: 0$ & 87 & 0.761 & 0.951 & 10.16 & $\mathrm{y}=0.6036 \mathrm{x}+3.7019$ \\
$\mathrm{C} 16: 0$ & 88 & 0.739 & 1.970 & 6.70 & $\mathrm{y}=0.5802 \mathrm{x}+12.316$ \\
$\mathrm{C} 18: 0$ & 86 & 0.778 & 1.680 & 11.25 & $\mathrm{y}=0.6623 \mathrm{x}+5.0268$ \\
$\mathrm{C} 18: 1 \mathrm{ln} 9 \mathrm{c}$ & 89 & 0.709 & 2.370 & 9.39 & $\mathrm{y}=0.497 \mathrm{x}+12.684$ \\
\hline
\end{tabular}

$\mathrm{n}$ - number of samples, $\mathrm{y}=\mathrm{bx}+\mathrm{a}=$ regression line, SEP - standard error of prediction, PCV - prediction coefficient of variation, $\mathrm{R}$ - correlation coefficient, C10:0 - caprinic acid, C12:0 - lauric acid, C14:0 - myristic acid, C16:0 - palmitic acid, C18:0 - stearic acid, C18:1n9c - oleic acid

Methods for determination of myristic, palmitic, and oleic acids with values of variance coefficient ranging from $0.60 \%$ to $1.25 \%(\mathrm{CCV})$ and from $6.70 \%$ to $10.16 \%(\mathrm{PCV})$ may be described as very reliable calibrations. The calibration for stearic acid determination only has a good reliability for correct prediction of results using the model $(\mathrm{CCV}=9.10 \% ; \mathrm{PCV}=11.25 \%)$, even though it attained the smallest differences between calibration and validation correlation coefficients. The calibration for lauric acid determination is only suitable for approximate determination of values, as the CCV value was at $2.81 \%$ and PCV at $18.88 \%$. Higher CCV and PCV values of caprinic acid calibration confirm our presumption concerning its unsuitability for analytic use as well as for approximate determination (CCV at $13.65 \%$; PCV at $26.41 \%$ ). This model was evaluated as the least reliable because a small margin of reference FA values was probable. Table 5 shows that the obtained values from both methods were not significantly different $(P>0.05)$. As the most reliable and robust calibration model to determine fatty acids in sheep milk appears to be the myristic acid model as it was characterized by high correlation coefficients with low standard errors $(0.999 \% \pm 0.056 \% ; 0.761 \% \pm 0.951 \%)$, and its reliability was confirmed also by the CCV and PCV values $(0.60 \%$ and $10.16 \%)$.

Table 5. Statistical evaluation of fatty acids (FA) in sheep milk.

\begin{tabular}{lccccccc}
\hline Indicator & $\mathrm{n}$ & $\mathrm{xNIR}(\%)$ & $\mathrm{xREF}(\%)$ & $\mathrm{S}_{\mathrm{x}}$ & $t_{\text {stat }}$ & $\mathrm{t}_{\text {krit }}$ & $\mathrm{t}_{\text {krit }}$ \\
\hline $\mathrm{C} 10: 0$ & 87 & 3.70 & 3.70 & 0.13 & $3.3 \mathrm{E}-16$ & 1.66 & 1.99 \\
$\mathrm{C} 12: 0$ & 87 & 2.35 & 2.35 & 0.06 & 0.00 & 0.50 & 1.66 \\
$\mathrm{C} 14: 0$ & 87 & 9.37 & 9.37 & 0.16 & -0.01 & 1.66 & 1.99 \\
$\mathrm{C} 16: 0$ & 88 & 29.43 & 29.43 & 0.31 & 0.00 & 1.66 & 1.99 \\
$\mathrm{C} 18: 0$ & 86 & 14.95 & 14.95 & 0.29 & $7.86 \mathrm{E}-05$ & 1.66 & 1.99 \\
$\mathrm{C} 18: 1 \mathrm{n} 9 \mathrm{c}$ & 89 & 25.27 & 25.27 & 0.02 & 0.00 & 1.66 & 1.99 \\
\hline
\end{tabular}

$\mathrm{n}$ - number of samples, xNIR - predicted values, xREF- reference values, $\mathrm{S}_{\mathrm{x}}-$ standard deviation, $t_{\text {stat }}-t$-test, $\mathrm{t} 1_{\text {krit }}$ - table value at $\alpha=0.05, \mathrm{t} 2{ }_{\text {krit }}-$ table value at $\alpha=0.01, \mathrm{C} 10: 0-$ caprinic acid, C12:0 - lauric acid, C14:0 myristic acid, C16:0 - palmitic acid, C18:0 - stearic acid, C18:1n9c-oleic acid

\section{Discussion}

An important diagnostic tool of PLS calibration is the dependency of PRESS (predicted residual sum of squares) on the number of factors used for calibration, enabling to estimate their optimal number. The PRESS value is the indicator of the PLS method calibration error. 
During an optimal course of PRESS, a steep decline of PLS occurs and further decline is gradual. A steep decline of the PRESS function therefore predicates about robustness of calibration model. A high number of PLS factors decreases prediction ability as the PRESS includes also spectral noise (Haaland and Thomas 1988).

The obtained correlation coefficients of calibration and validation (Tables 3 and 4) bear evidence that in all cases there was only a mesoscale dependence between reference values and predicted values. Achieving low correlation coefficients of validation and high values of standard errors was due to the fact that the concentration interval of fatty acids has a very narrow range and calibrations has to be enlarged by more standards for improving robustness and functionality. Due to this, the components concentration range increases reaching a more regular coverage of blind spots in calibration whereby determination error decreases (Dračková et al. 2008). It is also possible to obtain very high calibration and validation correlation coefficients with low determination errors at $0-50 \%$ concentration range of lauric, myristic, palmitic, and stearic acids.

Good calibration is considered to be CCV values around 10\% (PCV 15\%), reliable calibration CCV values lower than 5\% (PCV 10\%) (Čurda et al. 2002; Míka et al. 2008). Even though dependencies between reference and validation values have been found, some calibrations are only suitable for approximate determination of fatty acids in sheep milk, according to the achieved values of CCV and PCV.

Albanell et al. (2007) tried to create calibration models for non-homogenized sheep milk using NIRS Foss 5000 spectrophotometer to determine the contents of fat, proteins, casein, dry matter, capronic acid, caprylic acid, caprinic acid, myristic acid, palmitic acid, and oleic acid. Spectra were subjected to the first and second derivation and the PLS method was used for the setting of calibration models. The correlation coefficients obtained by calibration and their standard errors led to worse values than our results in almost all cases (Table 6). The correlation coefficients of calibration in other determined components ranged between 0.997 and 0.903 with low standard errors and validation from 0.995 to 0.718 . The team of authors obtained the best FA calibration values for determination of capronic and caprylic acids with calibration and validation correlation coefficients: 0.903 and 0.750 (capronic acid) and 0.914 and 0.718 (caprylic acid). The team of authors designed FT NIR spectroscopy in their paper as a potential technique for the prediction of concentration of fatty acids in sheep milk. Our study confirms this opinion. In order for our methods to be suitable for use in practice, calibration models have to be broadened by a higher number of standards to increase the concentration range of components, which would lead to lower standard errors of calibration and validation as well as higher correlation coefficients.

Table 6. Comparison of the results of calibration and validation of fatty acids of sheep milk obtained by Albanell et al. (2007) and our results.

\begin{tabular}{|c|c|c|c|c|}
\hline \multirow{2}{*}{ Fatty acid } & \multicolumn{2}{|c|}{ Calibration $(\mathrm{R} \pm \mathrm{SEC})$} & \multicolumn{2}{|c|}{ Validation $(\mathrm{R} \pm \mathrm{SEP})$} \\
\hline & Albanell et al. & Our results & Albanell et al. & Our results \\
\hline C10:0 & $0.866 \pm 0.395$ & $0.911 \pm 0.505$ & $0.651 \pm 0.660$ & $0.618 \pm 0.974$ \\
\hline C14:0 & $0.821 \pm 0.628$ & $0.999 \pm 0.056$ & $0.682 \pm 0.721$ & $0.761 \pm 0.951$ \\
\hline C16:00 & $0.857 \pm 0.952$ & $0.992 \pm 0.364$ & $0.718 \pm 1.273$ & $0.739 \pm 1.970$ \\
\hline C18:1n9c & $0.893 \pm 0.750$ & $0.999 \pm 0.152$ & $0.798 \pm 0.995$ & $0.709 \pm 2.370$ \\
\hline
\end{tabular}

$\mathrm{R}$ - correlation coefficient of calibration and validation, SEC - standard error of calibration, SEP - standard error of prediction, C10:0 - caprinic acid, C14:0 - myristic acid, C16:0 - palmitic acid, C18:1n9c-oleic acid 
Another published study dealt with determination of fatty acids in raw and dried cow milk (Coppa et al. 2010). Analyses were performed on a Foss NIRSystem 6500 spectrophotometer in transflectance mode in the spectral range of 400-2,498 nm. By means of the PLS method and by verification of cross calibration and by external validation (114 samples), high correlation coefficients for saturated FA (fatty acids), monounsaturated FA, transFA, trans and cis-C18:1, caprinic acid, lauric acid, myristic acid, palmitic acid, and oleic acid were achieved. When determining the same FA as in our study, the authors achieved better calibration results than we were able to achieve. The reason for higher accuracy of their calibration models apparently was the broad scale of samples they secured by obtaining them from cows that were in diverse feeding mode (grazing, silage, feed enriched with fat components), to ensure a broad range of fatty acid representation. They achieved only approximate prediction when determining polyunsaturated FAs, stearic acid, vaccenic acid, and conjugated linoleic acid. For determination of linoleic, $\alpha$-linolenic, and total n-6 and n-3 FAs, the prediction of their FA content was very weak. More reliable calibration models were achieved in case of FA determination in dried milk.

Reliable models for determination of myristic, palmitic and oleic acids were obtained; a reliable model for determination of stearic acid and a less reliable model for determination of lauric acid that is rather more suitable for approximate determination of values. The calibration model for determination of caprinic acid was totally unworkable.

It ensues from the results of our study that FT NIR spectroscopy is a method that can be used as a suitable and fast technique for analytical determination of concentration of fatty acids in majority representation in sheep milk.

\section{Acknowledgement}

This study was supported by the Ministry of Agriculture of the Czech Republic, project NAZV KUS QJ1230044.

\section{Reference}

Albanell E, Moussaoui Y, Caja G, Casals R, Salama AAK, Such X 2007: Determination of fat, protein, casein, total solids and fatty acids in ovine milk by near-infrared reflectance spectroscopy. In: International Symposium on the Challenge to Sheep and Goats Milk Sectors, Alghero, Italy, pp. 7-9

Aulrich K, Molkentin J 2009: Potential of near infrared spectroscopy for differentiation of organically and conventionally produced milk. Landbauforsch Volk 59: 301-308

Chen YJ, Iyo CH, Kawano S 1999: Development of calibration with sample cell compensation for determining the fat content of unhomogenised raw milk by a simple near infrared transmittance method. J Near Infrared Spec 7: 265-273

Coppa M, Ferlay A, Leroux CH, Jestin M, Chilliard Y, Martin B, Andueza D 2010: Prediction of milk fatty acid composition by near infrared reflectance spectroscopy. Int Dairy J 20: 182-189

Čurda L, Kukačková O, Novotná M 2002: Near-infrared spectroscopy and its application to milk and dairy products analysis. Chem Listy 96: $305-310$

De la Fuente MA, Ramos M, Recio I, Juárez, M 2013: Sheep milk. In: Milk and Dairy Products in Human Nutrition: Production, Composition and Health, John Wiley and Sons. Fort Valley, SA, pp. 554-577

Dračková M, Hadra L, Janštová B, Navrátilová P, Přidalová H, Vorlová L 2008: Analysis of goat milk by nearinfrared spectroscopy. Acta Vet Brno 77: 415-422

Haaland DM, Thomas EV 1988: Partial least-squares methods for spectral analyses. 2. Application to simulated and glass spectral data. Anal Chem 60: 1202-1208

Míka V, Kohoutek A, Nerušil P 2008: Spectroscopy in the near infrared region (NIR). The selection practical applications in agriculture. Methodology for practice (in Czech), Prague, $44 \mathrm{p}$.

Mlček J, Šustová K, Rop O, Juríková T, Humpolíček P, Balla S 2013: Rapid assessment of selected free amino acids during Edam cheese ripening by near infrared spectroscopy. Acta Vet Brno 82: 191-196

Mlček J, Rop O, Dohnal V, Šustová K 2011: Application of near infrared spectroscopy to estimate selected free amino acids and soluble nitrogen during cheese ripening. Acta Vet Brno 80: 293-297

Mlček J, Šustová K, Simeonovová J 2006: Application of FT NIR spectroscopy in the determination of basic chemical composition of pork and beef. Czech J Anim Sci 51: 361-368

Mouazen AM, Dridi S, Rouissi H, De Baerdemaeker J, Ramon H 2009: Prediction of selected ewe's milk properties and differentiating between pasture and box feeding using visible and near infrared spectroscopy. Biosyst Eng 104: 353-361 


\section{S34}

Nunez-Sanchez N, Garrido-Varo A, Serradilla J, Ares L 2002: Near infrared analysis of liquid and dried ewe milk. In: Near Infrared Spectroscopy: Proceedings $10^{\text {th }}$ International Conference, A. M. C. Davies, R. K. Cho, eds. NIR Publications. Chichester, UK, pp. 179-182

Procházková Z, Dračková M, Remešová A, Janštová B, Přidalová H, Vorlová L 2010: Use of near infrared spectroscopy to determine of the basic physico-chemical parameters of sheep's milk. Potravinárstvo 1: 70-73

Šustová K, Kuchtík J, Kráčmar S 2006: Analysis of ewe's milk by FT near infrared spectroscopy: measurement of samples on Petri dishes in reflectance mode. Acta Univ Agric Silvic. Mendelianae Brun 53: 131-138

Šustová K, Růžičková J, Kuchtík J 2007: Application of FT Near spectroscopy for determination of true protein and casein in milk. Czech J Anim Sci 52: 284-291 
Plate I

Lužová T. et al.: Determination... pp. S27-S34

\section{Stearic acid}

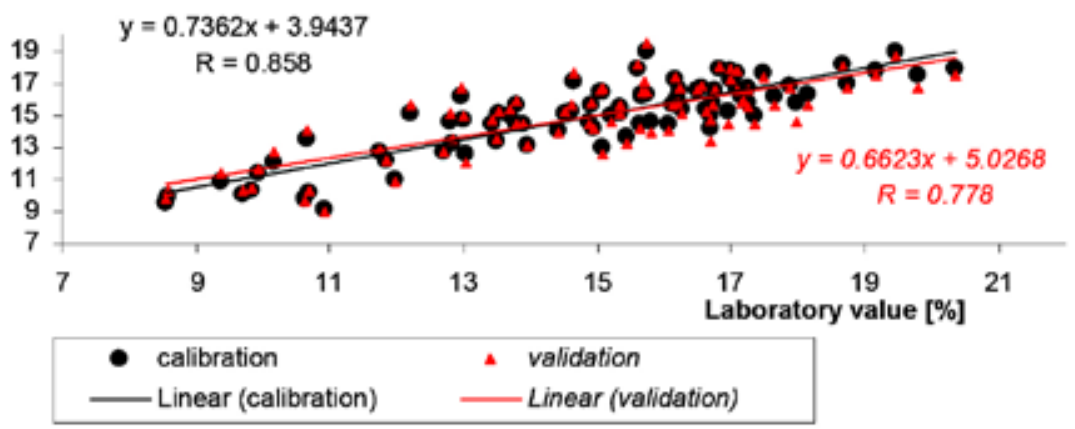

Fig. 2. Calibration and validation models for determination of stearic acid 